\title{
The Application of MIDI Music Production in College Music Teaching
}

\section{Cui Feng}

\author{
Moscow School of Arts, Weinan normal university Shanxi, Weinan, 714099
}

Keywords: MIDI music production; Music teaching; Impact of music; Role and value

\begin{abstract}
In the context of the new curriculum reform, music teachers, as an important element to achieve quality education, can also play an important role in cultivating students' musical qualities. With the continuous development of science and technology, music teaching has begun to permeate modern information technology. However, the traditional music teaching mode has gradually started to change under the background of the new curriculum reform. The innovative teaching mode of music has been applied in the actual music teaching process, which can play a vital role in music teaching, and then improve the quality and efficiency of music teaching. This paper studies the application of MIDI music production in music teaching.
\end{abstract}

\section{Introduction}

Music can train students 'extracurricular quality and play a great role in the students' musical emotion and interest cultivation. However, because there are many defects in our country's music teaching mode, which mainly manifests in the following aspects: the failure to pay attention to the choice of music teaching, the backward teaching mode of music, the imperfect music teaching equipment and others. All these phenomena will affect the students' learning of music and make music teaching fail to play its due role for students. In the background of the modern era, in order to ensure that music teaching can exert the expected influence and effect, it is necessary to improve the cultivation of students' musical emotion. MIDI, as a multimedia teaching tool, provides a new possibility for college music teaching, which helps music teaching to achieve a higher level and more efficient contribution.

\section{Current situation of MIDI music production in college music teaching}

With the continuous development of China's electronics industry, the scientific and technological content of teaching methods in colleges and universities began to gradually increase. Many countries have taken the lead in using electronic music technology in music teaching. By combining MIDI technology with computers, MIDI music production is realized. This is an unprecedented teaching reform to the pattern of the history of music teaching in our country. As a modern teaching method, the combination of MIDI technology and multimedia provides students with a brand-new music learning mode that is more visually intuitive and interactive and shows great prospect in future. The practical application shows that the application of MIDI music production to music teaching in colleges and universities not only improves the teaching mode of music in colleges and universities, but also further enriches the teaching contents. MIDI changes the music teaching into a more real and vivid one which is more abstract in the past. It also makes students active in music thinking and stimulates students' enthusiasm for music. For music teachers, it improves the quality of teaching music and teaching efficiency.

In the process of college music teaching, MIDI music production has a very broad development prospects. In the process of teaching music theory in colleges and universities, the practical application of MIDI technology has had a very big impact on the teaching concept and teaching mode of college music. With the reform of the new curriculum revolution, students' actual enthusiasm, initiative and creativity in the process of music teaching in colleges and universities is crucial, and these factors will be subject to the environment and mentality constraints. Therefore, college music teaching should first create a better teaching environment and atmosphere which can 
stimulate students' interest in learning music and creativity. Consequently efficient and high quality teaching can be achieved.

The integration of MIDI music production in college music teaching process can help students to experience the beauty of music more intuitively. Only through realizing the creative method and reverie of music, can students' subjective initiative be mobilized.

Compared with traditional monotonous music teaching methods, the application of MIDI music production in college music teaching makes the traditional dull music teaching more vivid and interesting. The application of MIDI music production in college music teaching makes the speed and methods of teaching more suitable for students, which brings richer music performance method that can stimulate students' interest.

\section{Introduction to the MIDI music teaching tools}

The composition of MIDI music tools mainly includes three parts: audio source, sequencer and input device. Among them, the sound source, as a material source for playing music, is like a bottle that can emit various sounds and it shows various musical forms. As the beginning of the music device, the sound source includes many different waveforms, which may show different temperaments in different environments. However, only the sound source itself cannot make the melody be played completely, which requires the command of sequencer Conduct. After analyzing various characteristics of the music, the sequencer will display the sound sources. The main music features include rhythm, tone and frequency speed, and the sequencer directs them mainly in the form of numbers Achieve. Input device as a connection device, music teacher plate through the actual interpretation of the music, through the connection device to achieve storage, so as to receive the sound, and finally complete the music teaching process.

\section{The analysis of the MIDI music tools' influence towards modern music teaching}

With the MIDI music production, music teachers can do the teaching through the presentation of different music effects to students in music training. It can stimulate students' interests in music learning, and can not only improve the quality of teaching and efficiency, but also enable students to feel the impact of modern information on music to help students better integrate into the atmosphere of music learning and ultimately achieve the goal of improving music learning ability. Applying the MIDI music production into music teaching process, music teachers can stimulate students' enthusiasm for music learning in the form of playing music. Such music teaching method can help students achieve the goal of self-training and the master of skills, which is beneficial to create a student-centered teaching model.

Specifically speaking, for example, in the process of teaching piano music, MIDI music production can enable students to appreciate the standard rhythm and promptly correct mistakes and improve deficiencies in the learning process so that students can get enhancement and improvement when correcting mistakes. The MIDI music production can vivify the sense of music, make the form of music more specific, expand students' music learning, and effectively enhance the students' feelings towards music. In the continuous development of information technology, music teachers can help students improve their sensitivity to music and intuitively perceive music images through the combination of MIDI music production and music teaching. This way would aid students to truly understand and perceive music and present their music skills more perfectly.

Applying MIDI music production into the teaching process, music teachers could guide students' independent learning of music and help students give full play to their subjective initiative and subjectivity, which would effectively ease the burden on music teachers and enable teachers to spend more time developing and sublimating students' musicality. MIDI music production can simulate a variety of musical instruments, which would help teachers to stimulate students' interest in music. Specifically, for example, in the process from recognizing to singing of the state, the tool can accurately locate each music rhythm and then present it in the form of music, not only to help students show their musical effects, but also to help students carry out error correction. The 
application of MIDI music production in Chinese college music teaching has effectively improved the quality and efficiency of our music teaching. Music teachers through the way of the production of MIDI music to guide students, and gradually make MIDI music production music teaching process has become an indispensable tool. Through the cultivation of students' musical emotion, the technique of student music performance has been sublimated, which effectively improves the quality of music teaching.

\section{Conclusions}

To sum up, mastering MIDI technology and familiarity are the basic skills that must be mastered in music teaching. Combining MIDI technology with music teaching is an issue that music teaching needs to pay attention to in the future. Teaching workers should only combine teaching content with the combination of advanced teaching methods can achieve the quality education of music teaching requirements. It is very necessary to carry out MIDI music course in colleges and universities in China. However, the application of MIDI technology in music teaching is also an effective way to reform music teaching.

\section{References}

[1] Li Xue. Application of MIDI Music Production in Music Teaching [J]. Grand View of Music, 2012(7).

[2] Zhao Yaqing. On MIDI Music Production and Vocal Music Teaching in Colleges and Universities [J]. Music Time and Space, 2013(16):113-113.

[3] Hu Weicheng. Talking about the Application of Computer Music Production System in College Music Teaching [J]. Motherland: Construction Edition, 2013(1):269-269.

[4] Liu Chunyu. MIDI Music Production in Music Teaching [J]. Exam Weekly, 2016(5):176-176.

[5] Ran Rui. Application of Computer Music Production System in College Music Teaching [J]. China Science and Technology Expo, 2009(2):149-150.

[6] Sui Yi. The Application of MIDI Technology in Music Teaching in Colleges and Universities [J]. Chinese Science and Education Innovation Guide, 2011(31):229-229. 